\title{
Determinants of Left Ventricular Systolic Function Improvement Following Coronary Artery Revascularization in Heart Failure Patients With Reduced Ejection Fraction (HFrEF)
}

\author{
Yusuke AdAchi, ${ }^{1}$ MD, Kenichi SAKaKura, ${ }^{1}$ MD, Hiroshi Wada, ${ }^{1}$ MD, Hiroshi FunaYama, ${ }^{1}$ MD, \\ Tomio Umemoto, ${ }^{1} \mathrm{MD}$, Hideo Fujita, ${ }^{1} \mathrm{MD}$, and Shin-ichi Momomura, ${ }^{1} \mathrm{MD}$
}

\begin{abstract}
SUMMARY
Revascularization therapy such as percutaneous coronary intervention (PCI) or coronary artery bypass grafting $(\mathrm{CABG})$ should be considered for heart failure with reduced ejection fraction (HFrEF). However, revascularization therapy does not always improve left ventricular ejection fraction (LVEF). The purpose of this study was to investigate the determinants of LVEF improvement following revascularization in HFrEF patients. From 2,229 consecutive decompensated heart failure patients, a total of $47 \mathrm{HFrEF}$ patients who underwent revascularization were included in the analysis. Improvement of LVEF was defined as [(LVEF during chronic phase) - (LVEF during acute phase)] $\geq 10 \%$. Univariate and multivariate logistic regression analyses were applied to investigate the determinants of LVEF improvement. The prevalence of revascularization by PCIs including chronic total occlusion (CTO) was significantly greater in the improved EF group $(45.0 \%)$ as compared to the non-improved EF group $(11.1 \%)(P=0.02)$. Multivariate logistic regression analysis revealed that revascularization by PCIs including CTO was the significant determinant of the LVEF improvement after adjusting for confounding factors (OR 5.43, 95\% CI 1.06-27.74, $P=0.04$ ). Optimal medical therapy (angiotensin-converting enzyme (ACE) inhibitor and/or angiotensin II receptor blocker (ARB) and beta-blockers) was less frequently prescribed in patients with $\mathrm{CABG}$ (50.0\% for ACE inhibitor and/or ARB and $41.7 \%$ for beta-blocker) than in patients without CABG $(94.3 \%$ for both) $(P<0.01$ and $P<0.001$, respectively). In conclusion, revascularization by PCIs including CTO was the significant determinant of LVEF improvement in HFrEF patients. Our results underscore the importance of optimal medical therapy even if patients receive complete revascularization such as CABG. (Int Heart J 2016; 57: 565-572)
\end{abstract}

Key words: Percutaneous coronary intervention, Coronary artery bypass grafting, Chronic total occlusion

$\mathrm{H}$ eart failure is a common disease with a prevalence of $1-2 \%$ in the adult population, ${ }^{1)}$ and still has high mortality in developed countries. One-year mortality rates in population-based studies have been reported to be $25 \%$ to $45 \% .^{2-5)}$ The mortality rate was higher in heart failure with reduced ejection fraction (HFrEF) than heart failure with preserved ejection fraction (HFpEF). ${ }^{6}$ Mortality rates of $\mathrm{HFrEF}$ (ejection fraction $<50 \%$ ) patients were reported to be $32 \%$ at one year and $68 \%$ at 5 years. ${ }^{6}$ The most common cause of HFrEF is coronary artery disease, which accounts for approximately two-thirds of HFrEF. ${ }^{\text {?) }}$

Revascularization therapy such as percutaneous coronary intervention (PCI) or coronary artery bypass grafting (CABG) should be considered in heart failure with coronary artery disease, and sometimes improves clinical outcomes including left ventricular function. ${ }^{8-12)}$ However, revascularization therapy is not always effective in heart failure with coronary artery disease. ${ }^{13)}$ It is unknown which types of patients receive the benefits such as improvement of left ventricular systolic function from revascularization. The purpose of this study was to investigate the determinants of left ventricular ejection fraction (LVEF) improvement following revascularization in HFrEF patients with coronary artery disease.

\section{Methods}

We identified 2,229 consecutive patients who were diagnosed as having decompensated heart failure including HFpEF and HFrEF regardless of etiology and were admitted to our department from 2006 to 2014. Patients who did not receive revascularization (PCI or CABG) during the hospitalization ( $n$ $=2,098$ ) were excluded. Because our study purpose was to investigate the determinants of LVEF improvement, it was important to compare echocardiographic findings including LVEF in the acute phase with those in the chronic phase (approximately 6 months from revascularization). Echocardiography in the acute phase was defined as echocardiography per-

From the ${ }^{1}$ Division of Cardiovascular Medicine, Saitama Medical Center, Jichi Medical University, Saitama, Japan.

Address for correspondence: Kenichi Sakakura, MD, Division of Cardiovascular Medicine, Saitama Medical Center, Jichi Medical University. 1-847 Amanuma-cho, Omiya-ku, Saitama, Saitama 330-8503 Japan. E-mail: ksakakura@ jichi.ac.jp

Received for publication February 17, 2016. Revised and accepted April 6, 2016

Released in advance online on J-STAGE September 13, 2016.

All rights reserved by the International Heart Journal Association. 
formed in the echocardiographic laboratory most recently from the day of discharge from the hospital for heart failure with the patient in a compensated state. Patients who underwent revascularization during the first hospitalization and received additional revascularization within one month from the first revascularization were included in the analysis $(n=2)$. In these cases, echocardiography which were performed most recently from the discharge day of the first hospitalization was adopted as the initial echocardiography. Echocardiography in the chronic phase was defined as echocardiography which was performed most recently 6 months after the initial echocardiography in the echocardiographic laboratory. Therefore, patients who did not receive echocardiography in the acute phase $(n=11)$ and patients who did not receive follow-up echocardiography in the chronic phase $(n=33)$ were excluded. In addition, we excluded patients who were diagnosed as heart failure with acute myocardial infarction (AMI) $(n=19)$. AMI was defined as a rise in cardiac enzyme concentrations (troponin I and/or T, and/or creatine phosphokinase-MB) with at least one value above the 99th percentile upper reference limit in the first 24 hours and with at least one of the following: 1) symptoms of ischemia, 2) new or presumed new significant ST-segment-T wave (ST-T) changes or new left bundle branch block (LBBB), 3) development of pathological Q waves in the electrocardiogram, 4) imaging evidence of new loss of viable myocardium or new regional wall motion abnormality, and 5) identification of an intracoronary thrombus by angiography or autopsy. ${ }^{14,15}$ ) Subacute myocardial infarction $(\leq 1$ week from onset) were also considered as AMI, whereas recent myocardial infarction ( $>1$ week from onset or unknown onset) were considered as old myocardial infarction, which were included in the present study. We excluded HFpEF patients (LVEF $\geq$ $50 \%{ }^{6,16)}$ at initial echocardiography) $(n=17)$. We also excluded patients who received cardiac resynchronization therapy (CRT) $(n=1)$ or surgical ventricular restoration $(n=3)$ during the hospitalization, which themselves may affect LVEF improvement.

Finally, a total of $47 \mathrm{HFrEF}$ patients (LVEF $<50 \%$ at initial echocardiography) who underwent revascularization during the hospitalization and received initial and follow-up echocardiography were included in the present study (Figure).

All of the transthoracic echocardiography was performed by skilled sonographers in our echocardiographic laboratory at a compensated state. Only echocardiographic findings that were measured by the sonographers and cardiologists in the echocardiographic laboratory were used in the present study, while echocardiographic findings that were measured at bedside were excluded. Left ventricular volume was calculated by the single-plane area-length method on an apical 4-chamber view. ${ }^{17)}$ Left ventricular ejection fraction (LVEF\%) was calculated from end-diastolic and end-systolic left ventricular volumes (LVEDV and LVESV) as (LVEDV - LVESV) x100/ LVEDV ${ }^{18)}$ Left ventricle diastolic diameter (LVDd) and systolic diameter (LVDs) were measured by M-mode echocardiography, and left atrial diameter (LAD) was also measured by Mmode echocardiography. Improvement of LVEF was defined as [(LVEF during chronic phase) - (LVEF during acute phase)] $\geq 10 \%$. $^{19,20)}$

At our institution, we usually follow the current guidelines when patients are referred for revascularization. ${ }^{21,22}$ Revascularization was considered for angiographically signifi-

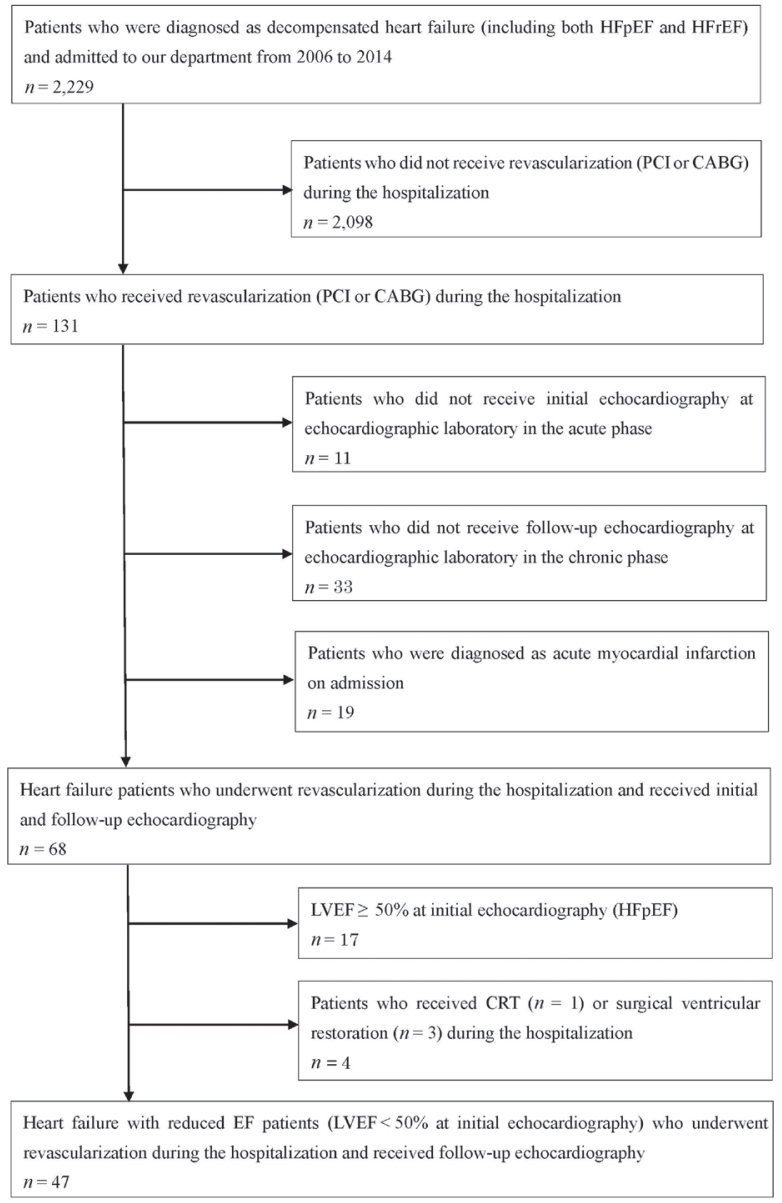

Figure. Flow chart of study population. HFpEF indicates heart failure with preserved ejection fraction; HFrEF, heart failure with reduced ejection fraction; $\mathrm{PCI}$, percutaneous coronary intervention; CABG, coronary artery bypass grafting; LVEF, left ventricle ejection fraction; and CRT, cardiac resynchronization therapy.

cant stenosis ( $\geq 75 \%$ diameter reduction by visual assessment) and functionally significant stenosis (fractional flow reserve measurement $<0.80$ ). Myocardial viability assessed by scintigraphy or echocardiography was considered for each PCI before revascularization. PCI was considered for patients with 1or 2-vessel disease, whereas CABG was considered for patients with 3-vessel or left main disease, and occasionally for patients with 1- or 2-vessel disease, including the proximal left anterior descending artery. With respect to the stent type, drugeluting stents were selected for small vessels (reference diameter $<2.5 \mathrm{~mm}$ ) or diffuse lesions ( $>30 \mathrm{~mm}$ ), whereas bare metal stents were selected for large vessels (reference diameter $>$ $4.0 \mathrm{~mm})$ or short lesions $(<20 \mathrm{~mm})$.

Clinical criteria were defined as follows. Hypertension was defined as systolic blood pressure $>140 \mathrm{mmHg}$, diastolic blood pressure $>90 \mathrm{mmHg}$, or medical treatment for hypertension on admission. Diabetes mellitus was defined as a hemoglobin A1c level in National Glycohemoglobin Standardization Program (NGSP) units $>6.5 \%$ or medical treatment for diabetes mellitus on admission. Dyslipidemia was defined as a low-density lipoprotein cholesterol level $>140 \mathrm{mg} / \mathrm{dL}$ or treat- 
ment for dyslipidemia on admission. Chronic kidney disease was defined as serum creatinine $>2.0 \mathrm{mg} / \mathrm{dL}$ on admission or on hemodialysis. Hyperuricemia was defined as serum uric acid $>7.0 \mathrm{mg} / \mathrm{dL}$ or treatment for hyperuricemia on admission. Anemia was defined as hemoglobin $<13 \mathrm{~g} / \mathrm{dL}$ (male) or $<12$ $\mathrm{g} / \mathrm{dL}$ (female) on admission. A chronic total occlusion (CTO) was defined as a complete coronary arterial obstruction with Thrombolysis In Myocardial Infarction (TIMI) flow grade of 0 for longer than (estimated) 3 months. ${ }^{23)}$ This study was approved by the institutional review board and written informed consent was waived because of the retrospective design.

Statistical analysis: All analyses were performed using the statistical software SPSS version 18 (SPSS, Inc., Chicago, IL, USA). All study patients were divided into the improved EF group (delta $\mathrm{LVEF} \geq 10 \%$ ) or non-improved EF group (delta LVEF < 10\%). We compared patient characteristics, echocardiographic findings, and types of revascularization between the groups. The categorical variables are presented as numbers (percentages) and were compared with Fisher's exact test. Continuous variables are presented as the mean \pm standard deviation (SD). The Shapiro-Wilk test was performed to determine whether the continuous variables were normally distributed. Normally distributed continuous variables were compared using the Student $t$ test. Otherwise, continuous variables were compared using the Mann-Whitney $U$-test. Univariate and multivariate logistic regression analyses were applied to investigate the determinants of the LVEF improvement. In the univariate logistic regression model, the dependent variable was LVEF improvement (delta LVEF $\geq 10 \%$ ), and independent variables were age, sex, and potential confounding factors that showed a marginal difference $(P<0.10)$ between the improved EF and non-improved EF groups. Odds ratios (OR) and 95\% confidence intervals (CI) were calculated. In the multivariate logistic regression model, the dependent variable was LVEF improvement (delta LVEF $\geq 10 \%$ ). Age, sex, and variables that showed a marginal association with LVEF improvement $(P<$ $0.10)$ in the univariate logistic regression analyses were adopt- ed as independent variables. OR and $95 \%$ CI were calculated. A value of $P<0.05$ was considered statistically significant.

\section{RESULTS}

A total of $47 \mathrm{HFrEF}$ patients were divided into the improved EF group $(n=20)$ and the non-improved EF group $(n=$ 27 ). The baseline characteristics of the study patients are shown in Table I. The mean age of the improved EF group (63.4 \pm 11.6 years) was comparable to that of the non-improved EF group $(65.4 \pm 10.3$ years $)(P=0.53)$. The prevalence of male sex in the improved EF group (75.0\%) was also comparable to that in the non-improved EF group (74.1\%) $(P$ $=1.00)$.

The transthoracic echocardiography findings of the study patients are shown in Table II. In the initial echocardiography, all parameters were comparable in the improved EF group and non-improved EF group. On the other hand, in the follow-up echocardiography, LVEF was significantly greater in the improved EF group $(54.4 \pm 7.9 \%)$ than in the non-improved EF group $(36.8 \pm 10.1 \%)(P<0.01)$, LVESV was significantly smaller in the improved EF group $(60.1 \pm 25.4 \mathrm{~mL})$ than in the non-improved EF group $(103.1 \pm 55.9 \mathrm{~mL})(P<0.01)$, and LVDs was significantly smaller in the improved EF group $(39.0 \pm 8.3 \mathrm{~mm})$ than in the non-improved EF group $(47.0 \pm$ $9.9 \mathrm{~mm})(P<0.01)$. The mean follow-up interval between initial and follow-up echocardiography was $8.0 \pm 10.7$ months. The mean echo follow-up interval was longer in the non-improved $\mathrm{EF}$ group $(8.3 \pm 14.0$ months $)$ than in the improved $\mathrm{EF}$ group (7.6 \pm 2.9$)$, although the difference was not statistically significant $(P=0.07)$. The mean interval from the last revascularization to follow-up echocardiography was $7.6 \pm 10.7$ months. The interval from the last revascularization to followup echocardiography in the improved EF group $(7.1 \pm 3.2$ months) was comparable to that in the non-improved EF group $(8.0 \pm 14.0$ months $)(P=0.11)$.

Table I. Patient Characteristics

\begin{tabular}{|c|c|c|c|c|}
\hline & $\begin{array}{c}\text { All } \\
(n=47)\end{array}$ & $\begin{array}{l}\text { Improved EF group } \\
\qquad(n=20)\end{array}$ & $\begin{array}{l}\text { Non-improved EF group } \\
\qquad(n=27)\end{array}$ & $P$ \\
\hline Age (years) & $64.5 \pm 10.8$ & $63.4 \pm 11.6$ & $65.4 \pm 10.3$ & 0.53 \\
\hline Male sex, $n(\%)$ & $35(74.5)$ & $15(75.0)$ & $20(74.1)$ & 1.00 \\
\hline $\operatorname{BMI}\left(\mathrm{kg} / \mathrm{m}^{2}\right)$ & $24.5 \pm 3.9$ & $25.6 \pm 4.6$ & $23.7 \pm 3.2$ & 0.20 \\
\hline Hypertension, $n(\%)$ & $37(78.7)$ & $18(90.0)$ & $19(70.4)$ & 0.15 \\
\hline Diabetes mellitus, $n(\%)$ & $22(46.8)$ & $8(40.0)$ & $14(51.9)$ & 0.56 \\
\hline Dyslipidemia, $n(\%)$ & $36(76.6)$ & $15(75.0)$ & $21(77.8)$ & 1.00 \\
\hline Chronic kidney disease, $n(\%)$ & $7(14.9)$ & $2(10.0)$ & $5(18.5)$ & 0.68 \\
\hline Hemodialysis, $n(\%)$ & $0(0)$ & $0(0)$ & $0(0)$ & - \\
\hline Hyperuricemia, $n(\%)$ & $38(80.9)$ & $16(80.0)$ & $22(81.5)$ & 1.00 \\
\hline Stroke, $n(\%)$ & $9(19.1)$ & $3(15.0)$ & $6(22.2)$ & 0.71 \\
\hline Anemia, $n(\%)$ & $17(36.2)$ & $6(30.0)$ & $11(40.7)$ & 0.55 \\
\hline Chronic obstructive pulmonary disease, $n(\%)$ & $1(2.1)$ & $1(5.0)$ & $0(0)$ & 0.43 \\
\hline Smoking, $n(\%)$ & $35(74.5)$ & $15(75.0)$ & $20(74.1)$ & 1.00 \\
\hline Old myocardial infarction, $n(\%)$ & $17(36.2)$ & $6(30.0)$ & $11(40.7)$ & 0.55 \\
\hline Atrial fibrillation, $n(\%)$ & $12(25.5)$ & $4(20.0)$ & $8(29.6)$ & 0.52 \\
\hline Previous hospitalization for heart failure, $n(\%)$ & $6(12.8)$ & $1(5.0)$ & $5(18.5)$ & 0.22 \\
\hline Post PPM, $n(\%)$ & $0(0)$ & $0(0)$ & $0(0)$ & - \\
\hline Post ICD, $n(\%)$ & $0(0)$ & $0(0)$ & $0(0)$ & - \\
\hline Post CRT, $n(\%)$ & $0(0)$ & $0(0)$ & $0(0)$ & - \\
\hline
\end{tabular}

Data are expressed as mean \pm SD or numbers $(\%)$. BMI indicates body mass index; PPM, permanent pacemaker; ICD, implantable cardioverter defibrillator; and CRT, cardiac resynchronization therapy. 
Table II. Transthoracic Echocardiography Findings

\begin{tabular}{|c|c|c|c|c|}
\hline & $\begin{array}{c}\text { All } \\
(n=47)\end{array}$ & $\begin{array}{l}\text { Improved EF group } \\
\qquad(n=20)\end{array}$ & $\begin{array}{l}\text { Non-improved EF group } \\
\qquad(n=27)\end{array}$ & $P$ \\
\hline \multicolumn{5}{|l|}{ Initial echocardiography } \\
\hline $\operatorname{LVEF}(\%)$ & $35.7 \pm 8.6$ & $33.4 \pm 6.4$ & $37.4 \pm 9.6$ & 0.11 \\
\hline LVEDV (mL) & $170.1 \pm 55.5$ & $173.9 \pm 50.9$ & $167.2 \pm 59.5$ & 0.48 \\
\hline LVESV (mL) & $111.4 \pm 46.0$ & $116.6 \pm 39.0$ & $107.6 \pm 50.9$ & 0.24 \\
\hline $\operatorname{LVDd}(\mathrm{mm})$ & $60.6 \pm 7.1$ & $61.5 \pm 6.9$ & $59.9 \pm 7.4$ & 0.46 \\
\hline LVDs (mm) & $49.7 \pm 8.4$ & $51.3 \pm 8.6$ & $48.5 \pm 8.2$ & 0.26 \\
\hline Left atrial diameter (mm) & $50.3 \pm 9.7$ & $50.5 \pm 6.9$ & $50.2 \pm 11.5$ & 0.34 \\
\hline \multicolumn{5}{|l|}{ Follow-up echocardiography } \\
\hline $\operatorname{LVEF}(\%)$ & $44.3 \pm 12.6$ & $54.4 \pm 7.9$ & $36.8 \pm 10.1$ & $<0.01$ \\
\hline LVEDV (mL) & $145.7 \pm 60.5$ & $130.1 \pm 47.1$ & $157.3 \pm 67.3$ & 0.16 \\
\hline LVESV (mL) & $84.8 \pm 49.9$ & $60.1 \pm 25.4$ & $103.1 \pm 55.9$ & $<0.01$ \\
\hline $\operatorname{LVDd}(\mathrm{mm})$ & $56.2 \pm 9.2$ & $53.7 \pm 8.0$ & $58.0 \pm 9.7$ & 0.11 \\
\hline LVDs (mm) & $43.6 \pm 10.0$ & $39.0 \pm 8.3$ & $47.0 \pm 9.9$ & $<0.01$ \\
\hline Left atrial diameter (mm) & $46.7 \pm 11.2$ & $45.8 \pm 9.2$ & $47.4 \pm 12.5$ & 0.67 \\
\hline Echo follow-up interval (months) & $8.0 \pm 10.7$ & $7.6 \pm 2.9$ & $8.3 \pm 14.0$ & 0.07 \\
\hline $\begin{array}{l}\text { Intervals from revascularization to follow-up } \\
\text { echocardiography (months) }\end{array}$ & $7.6 \pm 10.7$ & $7.1 \pm 3.2$ & $8.0 \pm 14.0$ & 0.11 \\
\hline
\end{tabular}

Data are expressed as mean \pm SD. LVEF indicates left ventricular ejection fraction; LVEDV, left ventricular end-diastolic volume; LVESV, left ventricular end-systolic volume; LVDd, left ventricular diastolic diameter; and LVDs, left ventricular systolic diameter.

Table III. Non-Pharmacological Intervention During Hospitalization

\begin{tabular}{|c|c|c|c|c|}
\hline & $\begin{array}{c}\text { All } \\
(n=47)\end{array}$ & $\begin{array}{c}\text { Improved EF group } \\
(n=20)\end{array}$ & $\begin{array}{c}\text { Non-improved EF group } \\
(n=27)\end{array}$ & $P$ \\
\hline Revascularization by PCIs including CTO, $n(\%)$ & $12(25.5)$ & $9(45.0)$ & $3(11.1)$ & 0.02 \\
\hline Revascularization by PCIs excluding CTO, $n(\%)$ & $23(48.9)$ & $9(45.0)$ & $14(51.9)$ & 0.77 \\
\hline Revascularization by CABG including CTO, $n(\%)$ & $7(14.9)$ & $2(10.0)$ & $5(18.5)$ & 0.68 \\
\hline Revascularization by CABG excluding CTO, $n(\%)$ & $5(10.6)$ & $0(0)$ & $5(18.5)$ & 0.06 \\
\hline Aortic valve replacement, $n(\%)$ & $1(2.1)$ & $0(0)$ & $1(3.7)$ & 1.00 \\
\hline Mitral valve replacement, $n(\%)$ & $0(0)$ & $0(0)$ & $0(0)$ & - \\
\hline Mitral valve plasty, $n(\%)$ & $1(2.1)$ & $0(0)$ & $1(3.7)$ & 1.00 \\
\hline Permanent pacemaker, $n(\%)$ & $0(0)$ & $0(0)$ & $0(0)$ & - \\
\hline Implantable cardioverter defibrillator, $n(\%)$ & $0(0)$ & $0(0)$ & $0(0)$ & - \\
\hline
\end{tabular}

Data are expressed as numbers (\%). PCI indicates percutaneous coronary intervention; CTO, chronic total occlusion; and CABG, coronary artery bypass grafting.

Table IV. Medication at Discharge

\begin{tabular}{|c|c|c|c|c|}
\hline & $\begin{array}{c}\text { All } \\
(n=47)\end{array}$ & $\begin{array}{l}\text { Improved EF group } \\
\qquad(n=20)\end{array}$ & $\begin{array}{l}\text { Non-improved EF group } \\
\qquad(n=27)\end{array}$ & $P$ \\
\hline ACE inhibitor and/or ARB, $n(\%)$ & $39(83.0)$ & $20(100.0)$ & $19(70.4)$ & 0.01 \\
\hline Beta-blocker, $n(\%)$ & $38(80.9)$ & $19(95.0)$ & $19(70.4)$ & 0.06 \\
\hline Alpha-blocker, $n(\%)$ & $1(2.1)$ & $0(0)$ & $1(3.7)$ & 1.00 \\
\hline Calcium channel blocker, $n(\%)$ & $8(17.0)$ & $3(15.0)$ & $5(18.5)$ & 1.00 \\
\hline Aldosterone receptor antagonist, $n(\%)$ & $21(44.7)$ & $11(55.0)$ & $10(37.0)$ & 0.25 \\
\hline Diuretic agent, $n(\%)$ & $40(85.1)$ & $18(90.0)$ & $22(81.5)$ & 0.68 \\
\hline Digitalis, $n(\%)$ & $2(4.3)$ & $1(5.0)$ & $1(3.7)$ & 1.00 \\
\hline Orally active cardiac stimulant, $n(\%)$ & $1(2.1)$ & $0(0)$ & $1(3.7)$ & 1.00 \\
\hline Amiodarone, $n(\%)$ & $5(10.6)$ & $0(0)$ & $5(18.5)$ & 0.06 \\
\hline Anticoagulant agent, $n(\%)$ & $24(51.1)$ & $9(45.0)$ & $15(55.6)$ & 0.56 \\
\hline Statin, $n(\%)$ & $39(83.0)$ & $19(95.0)$ & $20(74.1)$ & 0.11 \\
\hline Oral hypoglycemic agent, $n(\%)$ & $15(31.9)$ & $8(40.0)$ & $7(25.9)$ & 0.36 \\
\hline Insulin, $n(\%)$ & $11(23.4)$ & $3(15.0)$ & $8(29.6)$ & 0.31 \\
\hline
\end{tabular}

Data are expressed as numbers (\%). ACE inhibitor indicates angiotensin converting enzyme inhibitor; and ARB, angiotensin II receptor blocker.

Non-pharmacological interventions during the hospitalization such as PCI, CABG, valve replacement, and permanent pacemaker implantation are presented in Table III. PCI was performed in 35 patients, while CABG was performed in 12 patients. Complete revascularization was performed in $74.3 \%$ $(n=26)$ of the PCI group, whereas in $100.0 \%(n=12)$ of the $\mathrm{CABG}$ group. We classified the revascularization methods into 4 groups: PCIs including CTO, PCIs excluding CTO, CABG including CTO, and CABG excluding CTO. The prevalence of PCIs including CTO was significantly greater in the improved 
Table V. Comparison of CABG Group and non-CABG Group

\begin{tabular}{|c|c|c|c|c|}
\hline & $\begin{array}{c}\text { All } \\
(n=47)\end{array}$ & $\begin{array}{l}\text { CABG } \\
(n=12)\end{array}$ & $\begin{array}{l}\text { Non-CABG } \\
\quad(n=35)\end{array}$ & $P$ \\
\hline \multicolumn{5}{|l|}{ Patient characteristics } \\
\hline Age (years) & $64.5 \pm 10.8$ & $68.6 \pm 8.5$ & $63.1 \pm 11.3$ & 0.14 \\
\hline Male sex, $n(\%)$ & $35(74.5)$ & $6(50.0)$ & $29(82.9)$ & 0.05 \\
\hline BMI $\left(\mathrm{kg} / \mathrm{m}^{2}\right)$ & $24.5 \pm 3.9$ & $24.3 \pm 2.9$ & $24.6 \pm 4.3$ & 0.66 \\
\hline Hypertension, $n(\%)$ & $37(78.7)$ & $8(66.7)$ & $29(82.9)$ & 0.25 \\
\hline Diabetes mellitus, $n(\%)$ & $22(46.8)$ & $8(66.7)$ & $14(40.0)$ & 0.18 \\
\hline Dyslipidemia, $n(\%)$ & $36(76.6)$ & $11(91.7)$ & $25(71.4)$ & 0.24 \\
\hline Chronic kidney disease, $n(\%)$ & $7(14.9)$ & $2(16.7)$ & $5(14.3)$ & 1.00 \\
\hline Hemodialysis, $n(\%)$ & $0(0)$ & $0(0)$ & $0(0)$ & - \\
\hline Hyperuricemia, $n(\%)$ & $38(80.9)$ & $11(91.7)$ & $27(77.1)$ & 0.41 \\
\hline Stroke, $n(\%)$ & $9(19.1)$ & $5(41.7)$ & $4(11.4)$ & 0.04 \\
\hline Anemia, $n(\%)$ & $17(36.2)$ & $6(50.0)$ & $11(31.4)$ & 0.31 \\
\hline Chronic obstructive pulmonary disease, $n(\%)$ & $1(2.1)$ & $0(0)$ & $1(2.9)$ & 1.00 \\
\hline Smoking, $n(\%)$ & $35(74.5)$ & $5(41.7)$ & $30(85.7)$ & $<0.01$ \\
\hline Old myocardial infarction, $n(\%)$ & $17(36.2)$ & $3(25.0)$ & $14(40.0)$ & 0.49 \\
\hline Atrial fibrillation, $n(\%)$ & $12(25.5)$ & $3(25.0)$ & $9(25.7)$ & 1.00 \\
\hline Previous hospitalization for heart failure, $n(\%)$ & $6(12.8)$ & $4(33.3)$ & $2(5.7)$ & 0.03 \\
\hline Post PPM, $n(\%)$ & $0(0)$ & $0(0)$ & $0(0)$ & - \\
\hline Post ICD, $n(\%)$ & $0(0)$ & $0(0)$ & $0(0)$ & - \\
\hline Post CRT, $n(\%)$ & $0(0)$ & $0(0)$ & $0(0)$ & - \\
\hline \multicolumn{5}{|l|}{ Initial echocardiography } \\
\hline $\operatorname{LVEF}(\%)$ & $35.7 \pm 8.6$ & $36.1 \pm 11.5$ & $35.5 \pm 7.5$ & 0.85 \\
\hline LVEDV (mL) & $170.1 \pm 55.5$ & $173.5 \pm 57.2$ & $168.9 \pm 55.7$ & 0.81 \\
\hline LVESV (mL) & $111.4 \pm 46.0$ & $113.0 \pm 49.9$ & $110.9 \pm 45.3$ & 0.98 \\
\hline LVDd (mm) & $60.6 \pm 7.1$ & $59.7 \pm 8.4$ & $60.9 \pm 6.8$ & 0.61 \\
\hline LVDs (mm) & $49.7 \pm 8.4$ & $47.6 \pm 9.9$ & $50.4 \pm 7.9$ & 0.32 \\
\hline Left atrial diameter (mm) & $50.3 \pm 9.7$ & $51.4 \pm 15.1$ & $49.9 \pm 7.3$ & 0.63 \\
\hline Echo follow-up interval (months) & $8.0 \pm 10.7$ & $4.2 \pm 3.2$ & $9.3 \pm 12.0$ & 0.01 \\
\hline $\begin{array}{l}\text { Intervals from revascularization to follow-up } \\
\text { echocardiography (months) }\end{array}$ & $7.6 \pm 10.7$ & $3.8 \pm 3.1$ & $8.9 \pm 12.1$ & 0.01 \\
\hline \multicolumn{5}{|l|}{ Medication } \\
\hline ACE inhibitor and/or ARB, $n(\%)$ & $39(83.0)$ & $6(50.0)$ & $33(94.3)$ & $<0.01$ \\
\hline Beta-blocker, $n(\%)$ & $38(80.9)$ & $5(41.7)$ & $33(94.3)$ & $<0.001$ \\
\hline Alpha-blocker, $n(\%)$ & $1(2.1)$ & $0(0)$ & $1(2.9)$ & 1.00 \\
\hline Calcium channel blocker, $n(\%)$ & $8(17.0)$ & $2(16.7)$ & $6(17.1)$ & 1.00 \\
\hline Aldosterone receptor antagonist, $n(\%)$ & $21(44.7)$ & $4(33.3)$ & $17(48.6)$ & 0.51 \\
\hline Diuretic agent, $n(\%)$ & $40(85.1)$ & $10(83.3)$ & $30(85.7)$ & 1.00 \\
\hline Digitalis, $n(\%)$ & $2(4.3)$ & $0(0)$ & $2(5.7)$ & 1.00 \\
\hline Orally active cardiac stimulant, $n(\%)$ & $1(2.1)$ & $0(0)$ & $1(2.9)$ & 1.00 \\
\hline Amiodarone, $n(\%)$ & $5(10.6)$ & $3(25.0)$ & $2(5.7)$ & 0.10 \\
\hline Anticoagulant agent, $n(\%)$ & $24(51.1)$ & $8(66.7)$ & $16(45.7)$ & 0.32 \\
\hline Statin, $n(\%)$ & $39(83.0)$ & $9(75.0)$ & $30(85.7)$ & 0.40 \\
\hline Oral hypoglycemic agent, $n(\%)$ & $15(31.9)$ & $2(16.7)$ & $13(37.1)$ & 0.29 \\
\hline Insulin, $n(\%)$ & $11(23.4)$ & $5(41.7)$ & $6(17.1)$ & 0.12 \\
\hline
\end{tabular}

Data are expressed as numbers $(\%)$ or mean \pm SD. BMI indicates body mass index; PPM, permanent pacemaker; ICD, implantable cardioverter defibrillator; CRT, cardiac resynchronization therapy; LVEF, left ventricular ejection fraction; LVEDV, left ventricular end-diastolic volume; LVESV, left ventricular end-systolic volume; LVDd, left ventricular diastolic diameter; LVDs, left ventricular systolic diameter; ACE inhibitor, angiotensin converting enzyme inhibitor; and ARB, angiotensin II receptor blocker.

EF group $(45.0 \%)$ compared to the non-improved EF group $(11.1 \%)(P=0.02)$. The prevalence of PCIs excluding CTO in the improved $\mathrm{EF}$ group (45.0\%) was comparable to that in the non-improved EF group (51.9\%) $(P=0.77)$. The prevalence of CABG including CTO in the improved EF group (10.0\%) was also comparable to that in the non-improved EF group (18.5\%) $(P=0.68)$. Surprisingly, the prevalence of CABG excluding CTO was greater in the non-improved EF group (18.5\%) than in the improved EF group (0\%), although the difference was not statistically significant $(P=0.06)$.

Medications at discharge are shown in Table IV. The prevalence of angiotensin converting enzyme inhibitor (ACE inhibitor) and/or angiotensin II receptor blocker (ARB) in the improved EF group (100.0\%) was significantly greater than in the non-improved EF group $(70.4 \%)(P<0.01)$, whereas the prevalence of beta-blocker in the improved EF group (95.0\%) was marginally different from that in the non-improved $\mathrm{EF}$ group $(70.4 \%)(P=0.06)$.

We also analyzed the characteristics of patients who received CABG as revascularization, and compared with nonCABG (= PCI) patients (Table V). In patients with CABG, the prescription rate of an ACE inhibitor and/or ARB was significantly lower $(50.0 \%)$ than in patients without CABG $(94.3 \%)$ $(P<0.01)$. The use of a beta-blocker was also significantly lower in patients with CABG $(41.7 \%)$ than in patients without CABG $(94.3 \%)(P<0.001)$. 
Table VI. Determinants of LVEF Improvement: Univariate and Multivariate Logistic Regression Analysis

\begin{tabular}{|c|c|c|c|c|c|c|}
\hline \multirow[b]{3}{*}{ Independent variables } & \multicolumn{6}{|c|}{ Determinant variable: $\mathrm{LVEF}$ improvement (delta $\mathrm{LVEF} \geq 10 \%$ ) } \\
\hline & \multicolumn{3}{|c|}{ Univariate Logistic Regression Analysis } & \multicolumn{3}{|c|}{ Multivariate Logistic Regression Analysis } \\
\hline & OR & $95 \% \mathrm{CI}$ & $P$ & OR & $95 \% \mathrm{CI}$ & $P$ \\
\hline Age ( 1 year increase) & 0.98 & 0.93-1.04 & 0.52 & 0.99 & $0.93-1.05$ & 0.72 \\
\hline Male & 0.95 & $0.25-3.60$ & 0.94 & 2.29 & $0.38-13.71$ & 0.36 \\
\hline Echo follow-up interval (1 month increase) & 0.99 & $0.94-1.05$ & 0.81 & & & \\
\hline Revascularization by PCIs including CTO & 6.55 & $1.48-29.01$ & 0.01 & 5.43 & $1.06-27.74$ & 0.04 \\
\hline Revascularization by PCIs excluding CTO & 0.76 & $0.24-2.42$ & 0.64 & & & \\
\hline Revascularization by CABG including CTO & 0.49 & $0.09-2.83$ & 0.42 & & & \\
\hline Revascularization by CABG excluding CTO* & N/A & N/A & N/A & & & \\
\hline $\mathrm{ACE}$ inhibitor and/or $\mathrm{ARB}^{* *}$ & N/A & N/A & N/A & & & \\
\hline Beta-blocker & 8.00 & $0.91-70.34$ & 0.06 & 5.87 & $0.52-66.66$ & 0.15 \\
\hline Amiodarone ${ }^{*}$ & N/A & N/A & N/A & & & \\
\hline
\end{tabular}

Univariate logistic regression analysis was performed to identify variables that had marginal association with LVEF improvement $(P<0$. 10$)$. Age, sex and all variables that had marginal association in univariate analysis were adopted as independent variables in multivariate logistic regression analysis. ${ }^{*}$ Revascularization by $\mathrm{CABG}$ excluding $\mathrm{CTO}$ and amiodarone were not applicable for univariate logistic regression analysis because there were no patients in the improved EF group. ${ }^{* *} \mathrm{ACE}$ inhibitor and/or ARB were not applicable for univariate logistic regression analysis because all patients in the improved EF group were prescribed ACE inhibitors and/or ARB. OR indicates odds ratio; CI, confidence interval; LVEF, left ventricle ejection fraction; PCI, percutaneous coronary intervention; CTO, chronic total occlusion; CABG, coronary artery bypass grafting; ACE inhibitor, angiotensin converting enzyme inhibitor; ARB, angiotensin II receptor blocker; and N/A, not applicable.

The results of univariate and multivariate logistic regression analyses for the improved EF group are shown in Table VI. In the univariate logistic regression analysis, independent variables were age, sex, methods of revascularization, and potential confounding factors that showed a marginal difference $(P<0.10)$ between the improved EF and non-improved EF groups in Table I-IV. Revascularization by CABG excluding CTO and amiodarone were not applicable for univariate logistic regression analysis because there were no patients in the improved EF group. ACE inhibitors and/or ARB were not applicable for univariate logistic regression analysis because all patients of the improved EF group received an ACE inhibitor and/or ARB. In the multivariate logistic regression analysis, age, sex, and variables that showed a marginal association $(P<$ $0.10)$ with LVEF improvement in the univariate logistic regression analyses were adopted as independent variables. Revascularization by PCIs including CTO (OR 5.43, 95\% CI 1.06$27.74, P=0.04$ ) was the significant determinant of LVEF improvement in this multivariate analysis.

\section{DiscusSiON}

From among 2,229 heart failure patients admitted to our department, we extracted $47 \mathrm{HFrEF}$ patients who underwent revascularization (PCI or CABG) during the hospitalization, and analyzed to identify the determinants of LVEF improvement following revascularization. ACE inhibitors and/or ARB were prescribed to all patients in the improved EF group, and beta-blockers were also prescribed to $95 \%$ of patients in the improved EF group. Multivariate logistic regression analysis revealed that revascularization by PCIs including CTO was the only significant determinant of LVEF improvement after adjusting for the confounding factors.

In the present study, CABG was not a determinant of LVEF improvement, which contradicts earlier studies such as CREDO-Kyoto PCI/CABG Registry data that showed CABG is associated with better survival outcomes than PCI in patients with reduced $\mathrm{LVEF}^{24)}$ To explain this contradiction, there are several confounding factors regarding the association between CABG and LVEF improvement in the present study. First, the most significant confounding factor is the difference in the prescription rate of optimal medical therapy. The prescription rate of optimal medical therapy including ACE inhibitors and/or $\mathrm{ARB}$ and beta-blockers was significantly lower in patients with CABG than in patients without CABG $(P<0.01$ and $P<$ 0.001 , respectively). Second, the echo follow-up intervals were significantly shorter in the patients with CABG $(4.2 \pm 3.2$ months) than in the patients without CABG $(9.3 \pm 12.0$ months). Therefore, we might have missed the LVEF improvement in the later phase in the patients with CABG. Furthermore, a previous history of stroke and heart failure hospitalization were more common in the patients with $\mathrm{CABG}$, suggesting that the severity of arteriosclerosis or heart failure was greater in the patients in the CABG group. Given these confounding factors, our results may underscore the importance of optimal medical therapy even if the patient receives CABG.

It is well known that coronary CTO is associated with poor clinical outcomes such as acute myocardial infarction or sudden cardiac death. ${ }^{25-27)}$ Successful revascularization of coronary CTO is associated with the improvement of left ventricular function in patients with angina pectoris or old myocardial infarction. ${ }^{28-30)}$ Recently, George and colleagues reported that successful CTO intervention was associated with a decrease in mortality as compared to unsuccessful CTO intervention using large registry data $(n=13,443) .{ }^{31)}$ Furthermore, Jang and colleagues reported the long-term survival benefit of CTO revascularization as compared to medical therapy using a propensity score-matched population. ${ }^{32)}$ However, the association between improvement of LV systolic function and revascularization of coronary CTO has not been investigated in patients with heart failure. Our study focused on a systolic heart failure population, and showed the possible benefit of CTO revascularization for LV systolic function improvement. Since LV systolic function is a significant predictor of long-term outcome in patients 
with heart failure, ${ }^{33-36)}$ improvement of LV systolic function following CTO revascularization may improve long-term clinical outcomes in HFrEF patients if performed together with optimal medical therapy.

There have been technical issues in PCI to coronary CTO. While the success rate of PCI to coronary CTO was not sufficient $\left(51-74 \%\right.$ ) until $2009,{ }^{37,38)}$ the introduction of new devices such as guidewires or microcatheters and bidirectional approaches (antegrade and retrograde) has significantly increased the initial success rate of CTO ${ }^{39-41)}$ Furthermore, the long-term patency of revascularized CTO was low in patients treated using bare-metal stents, ${ }^{42)}$ however, the long-term patency of revascularized CTO is comparable to non-CTO lesions in patients treated by drug-elution stents. ${ }^{43)}$ Therefore, PCI to CTO is not a special procedure, and patency following drugeluting stent deployment is to be expected.

Study limitations: Since the present study was designed as a single-center, retrospective, and observational study, there is a possibility of patient selection bias. LVEF was measured using the single plane area-length method, which is less accurate than the bi-plane modified Simpson method. Therefore, the overestimation or underestimation of LVEF was possible. Echocardiographic parameters that were performed before revascularization should be used as initial parameters. However, some cases received only bedside echocardiography that did not include full parameters before revascularization. Therefore, we adopted the echocardiography performed in the echocardiographic laboratory most recently from the day of discharge as the initial echocardiography. Furthermore, the interval between the initial echocardiography and the follow-up echocardiography was not consistent, which may have affected the improvement of LVEF. It would be better to evaluate myocardial viability using stress scintigraphy before revascularization, nevertheless, it was sometimes difficult to perform the stress test for heart failure patients. In most cases, we evaluated myocardial viability by myocardial wall thickness assessed by echocardiography. Finally, although we discussed the indication of revascularization for each patient with coronary artery disease and followed clinical guidelines ${ }^{21)}$ in our daily clinical practice, there was a still selection bias regarding the indication of revascularization.

Conclusions: Revascularization by PCIs including CTO was the significant determinant of LVEF improvement in HFrEF patients under optimal medical therapy. A low prescription rate for optimal medical therapy may counteract the merit of revascularization by CABG. Our results suggest the possible benefit of CTO PCI in HFrEF patients. Our results also underscore the importance of optimal medical therapy even if patients receive complete revascularization such as $\mathrm{CABG}$.

\section{ACKNOWLEDGMENT}

We are grateful for the support of the entire staff of the echocardiography laboratory of Saitama Medical Center, Jichi Medical University.

\section{Disclosure}

Conflict of interest: Dr. Sakakura received speaking honorari- um from Abbott Vascular, Boston Scientific, Medtronic Cardiovascular, and Terumo.

\section{REFERENCES}

1. McMurray JJ, Pfeffer MA. Heart failure. Lancet 2005; 365: 187789. (Review)

2. Ho KK, Anderson KM, Kannel WB, Grossman W, Levy D. Survival after the onset of congestive heart failure in Framingham Heart Study subjects. Circulation 1993; 88: 107-15.

3. Zannad F, Briancon S, Juilliere Y, et al. Incidence, clinical and etiologic features, and outcomes of advanced chronic heart failure: the EPICAL Study. Epidémiologie de l'Insuffisance Cardiaque Avancée en Lorraine. J Am Coll Cardiol 1999; 33: 734-42.

4. Senni M, Tribouilloy CM, Rodeheffer RJ, et al. Congestive heart failure in the community: a study of all incident cases in Olmsted County, Minnesota, in 1991. Circulation 1998; 98: 2282-9.

5. MacIntyre K, Capewell S, Stewart S, et al. Evidence of improving prognosis in heart failure: trends in case fatality in 66547 patients hospitalized between 1986 and 1995. Circulation 2000; 102: 112631.

6. Owan TE, Hodge DO, Herges RM, Jacobsen SJ, Roger VL, Redfield MM. Trends in prevalence and outcome of heart failure with preserved ejection fraction. N Engl J Med 2006; 355: 251-9.

7. McMurray JJ, Adamopoulos S, Anker SD, et al. ESC Guidelines for the diagnosis and treatment of acute and chronic heart failure 2012: The Task Force for the Diagnosis and Treatment of Acute and Chronic Heart Failure 2012 of the European Society of Cardiology. Developed in collaboration with the Heart Failure Association (HFA) of the ESC. Eur Heart J 2012; 33: 1787-847.

8. Mule JD, Bax JJ, Zingone B, et al. The beneficial effect of revascularization on jeopardized myocardium: reverse remodeling and improved long-term prognosis. Eur J Cardiothorac Surg 2002; 22: 426-30.

9. Vanoverschelde JL, Depré C, Gerber BL, et al. Time course of functional recovery after coronary artery bypass graft surgery in patients with chronic left ventricular ischemic dysfunction. Am J Cardiol 2000; 85: 1432-9.

10. Tarakji KG, Brunken R, McCarthy PM, et al. Myocardial viability testing and the effect of early intervention in patients with advanced left ventricular systolic dysfunction. Circulation 2006; 113: 230-7.

11. Rossi JS, Flaherty JD, Fonarow GC, et al. Influence of coronary artery disease and coronary revascularization status on outcomes in patients with acute heart failure syndromes: a report from OPTIMIZE-HF (Organized Program to Initiate Lifesaving Treatment in Hospitalized Patients with Heart Failure). Eur J Heart Fail 2008; 10: $1215-23$

12. Allman KC, Shaw LJ, Hachamovitch R, Udelson JE. Myocardial viability testing and impact of revascularization on prognosis in patients with coronary artery disease and left ventricular dysfunction: a meta-analysis. J Am Coll Cardiol 2002; 39: 1151-8.

13. Velazquez EJ, Lee KL, Deja MA, et al. Coronary-artery bypass surgery in patients with left ventricular dysfunction. $\mathrm{N}$ Engl J Med 2011; 364: 1607-16.

14. Thygesen K, Alpert JS, Jaffe AS, et al. Third universal definition of myocardial infarction. J Am Coll Cardiol 2012; 60: 1581-98.

15. Montalescot G, Dallongeville J, Van Belle E, et al. STEMI and NSTEMI: are they so different? 1 year outcomes in acute myocardial infarction as defined by the ESC/ACC definition (the OPERA registry). Eur Heart J 2007; 28: 1409-17.

16. Iwano $\mathrm{H}$, Little WC. Heart failure: what does ejection fraction have to do with it? J Cardiol 2013; 62: 1-3. (Review)

17. Helak JW, Reichek N. Quantitation of human left ventricular mass and volume by two-dimensional echocardiography: in vitro anatomic validation. Circulation 1981; 63: 1398-407.

18. Ghio S, Freemantle N, Serio A, et al. Baseline echocardiographic characteristics of heart failure patients enrolled in a large European 
multicentre trial (CArdiac REsynchronisation Heart Failure study). Eur J Echocardiogr 2006; 7: 373-8.

19. Imamura T, Kinugawa K, Nitta D, Komuro I. Complete left bundle branch block and smaller left atrium are predictors of response to cardiac resynchronization therapy in advanced heart failure. Circ J 2015; 79: 2414-21.

20. Yeh JK, Hsiao YC, Jian CR, et al. Comparison of Baseline versus Posttreatment Left Ventricular Ejection Fraction in Patients with Acute Decompensated Heart Failure for Predicting Cardiovascular Outcome: Implications from Single-Center Systolic Heart Failure Cohort. PLoS One 2016; 11: e0145514.

21. JCS Joint Working Group. Guidelines for elective percutaneous coronary intervention in patients with stable coronary artery disease (JCS 2011) published in 2012--digest version. Circ J 2013; 77: 1590-607.

22. Wakabayashi Y, Wada H, Sakakura K, et al. Major adverse cardiac and bleeding events associated with non-cardiac surgery in coronary artery disease patients with or without prior percutaneous coronary intervention. J Cardiol 2015; 66: 341-6.

23. Stone GW, Kandzari DE, Mehran R, et al. Percutaneous recanalization of chronically occluded coronary arteries: a consensus document: part I. Circulation 2005; 112: 2364-72.

24. Marui A, Kimura T, Nishiwaki N, et al. Comparison of five-year outcomes of coronary artery bypass grafting versus percutaneous coronary intervention in patients with left ventricular ejection fractions $\leq 50 \%$ versus $>50 \%$ (from the CREDO-Kyoto PCI/CABG Registry Cohort-2). Am J Cardiol 2014; 114: 988-96.

25. Nishiyama K, Shizuta S, Doi T, Morimoto T, Kimura T. Sudden cardiac death after PCI and CABG in the bare-metal stent era: Incidence, prevalence, and predictors. Int J Cardiol 2010; 144: 263 6.

26. Mizuguchi Y, Takahashi A, Yamada T, Taniguchi N, Nakajima S, Hata T. Chronic total occlusion in a non-infarct-related coronary artery exacerbates prognosis in acute myocardial infarction: a Japanese single-center retrospective study. Int J Cardiol 2014; 176: 1139-41.

27. Mizuguchi Y, Takahashi A, Hashimoto S, et al. Impact of the Presence of Chronic Total Occlusion in a Non-Infarct-Related Coronary Artery in Acute Myocardial Infarction Patients. Int Heart J 2015; 56: 592-6.

28. Chung CM, Nakamura S, Tanaka K, et al. Effect of recanalization of chronic total occlusions on global and regional left ventricular function in patients with or without previous myocardial infarction. Catheter Cardiovasc Interv 2003; 60: 368-74.

29. Melchior JP, Doriot PA, Chatelain P, et al. Improvement of left ventricular contraction and relaxation synchronism after recanalization of chronic total coronary occlusion by angioplasty. J Am Coll Cardiol 1987; 9: 763-8.

30. Sirnes PA, Myreng Y, Mølstad P, Bonarjee V, Golf S. Improvement in left ventricular ejection fraction and wall motion after successful recanalization of chronic coronary occlusions. Eur Heart J 1998; 19: 273-81.
31. George S, Cockburn J, Clayton TC, et al. Long-term follow-up of elective chronic total coronary occlusion angioplasty: analysis from the U.K. Central Cardiac Audit Database. J Am Coll Cardiol 2014; 64: 235-43.

32. Jang WJ, Yang JH, Choi SH, et al. Long-term survival benefit of revascularization compared with medical therapy in patients with coronary chronic total occlusion and well-developed collateral circulation. JACC Cardiovasc Interv 2015; 8: 271-9.

33. Gottdiener JS, McClelland RL, Marshall R, et al. Outcome of congestive heart failure in elderly persons: influence of left ventricular systolic function. The Cardiovascular Health Study. Ann Intern Med 2002; 137: 631-9.

34. Vasan RS, Larson MG, Benjamin EJ, Evans JC, Reiss CK, Levy D. Congestive heart failure in subjects with normal versus reduced left ventricular ejection fraction: prevalence and mortality in a population-based cohort. J Am Coll Cardiol 1999; 33: 1948-55.

35. Risk stratification and survival after myocardial infarction. N Engl J Med 1983; 309: 331-6.

36. Kambara H, Nakagawa M, Kinoshita M, Kawai C. Long-term prognosis after myocardial infarction: univariate and multivariate analysis of clinical characteristics in 1,000 patients. Kyoto and Shiga Myocardial Infarction (KYSMI) Study Group. Clin Cardiol 1993; 16: 872-8.

37. Joyal D, Afilalo J, Rinfret S. Effectiveness of recanalization of chronic total occlusions: a systematic review and meta-analysis. Am Heart J 2010; 160: 179-87. (Review)

38. Arslan U, Balcioglu AS, Timurkaynak T, Cengel A. The clinical outcomes of percutaneous coronary intervention in chronic total coronary occlusion. Int Heart J 2006; 47: 811-9.

39. Mitsudo K, Yamashita T, Asakura Y, et al. Recanalization strategy for chronic total occlusions with tapered and stiff-tip guidewire. The results of CTO new techniQUE for STandard procedure (CONQUEST) trial. J Invasive Cardiol 2008; 20: 571-7.

40. Fang HY, Lee CH, Fang CY, et al. Application of penetration device (Tornus) for percutaneous coronary intervention in balloon uncrossable chronic total occlusion-procedure outcomes, complications, and predictors of device success. Catheter Cardiovasc Interv $2011 ; 78: 356-62$.

41. Rathore S, Katoh O, Tuschikane E, Oida A, Suzuki T, Takase S. A novel modification of the retrograde approach for the recanalization of chronic total occlusion of the coronary arteries intravascular ultrasound-guided reverse controlled antegrade and retrograde tracking. JACC Cardiovasc Interv 2010; 3: 155-64.

42. Sheiban I, Moretti C, Kumar P, et al. Immediate and medium-term outcomes following the treatment of very long ( $>$ or $=50 \mathrm{~mm}$ ) chronic total coronary artery occlusions. J Invasive Cardiol 2004; 16: 5-9.

43. Colmenarez HJ, Escaned J, Fernández C, et al. Efficacy and safety of drug-eluting stents in chronic total coronary occlusion recanalization: a systematic review and meta-analysis. J Am Coll Cardiol 2010; 55: 1854-66. (Review) 